\title{
Al-Graphite Composites Prepared by Powder Metallurgy Applying an Innovative Sintering Route, Which Avoids Carbides Formation
}

\author{
J.M. Mendoza-Duarte ${ }^{1}$, F.C. Robles-Hernandez ${ }^{2}$, C. Carreño-Gallardo ${ }^{1}$, I. Estrada-Guel ${ }^{1}$, R. \\ Martínez-Sánchez ${ }^{1}$ \\ ${ }^{1}$ Centro de Investigación en Materiales Avanzados (CIMAV). Laboratorio Nacional de \\ Nanotecnología Miguel de Cervantes No. 120, 31136, Chihuahua, Chih., Mexico. \\ 2 Department of Mechanical Engineering Technology, University of Houston, Houston, TX \\ 77204-4020, USA.
}

The aluminum matrix composites (AMC) are an attractive group of materials with applications in automotive and aerospace industries due to their higher strength and lighter weight [1]. AMC can be processed by mechanical milling (MM); this technique can disperse hard phases into the aluminum matrix achieving an enhanced on the mechanical response of samples [2]. With graphite addition in the AMC, it is possible to obtain a better mechanical performance $[3,4]$. However, due to the use of high temperature and prolonged sintering time (normally associated to conventional sintering) the aluminum carbide $\left(\mathrm{Al}_{4} \mathrm{C}_{3}\right)$ phase is formed $[5,6]$.

This work deals with the analysis of microstructural changes observed in Al-Gr composites prepared by mechanical milling (MM) following two different sintering routes: the conventional method (CM), which includes the cold compaction of powders and pressure-less sintering in a furnace for an extended period of time (hours). In contrast, the high frequency induction sintering (HFIS) method applies the simultaneous application of pressure and heat, reaching high densities in minutes.

The first step was the nanostructured Al-Gr powders preparation by MM. The graphite was mechanically "activated" increasing its surface area in a SPEX 8000M mill (8 hours). Some mixtures composed by $\mathrm{Al}$ powder and the activated graphite (1 in wt.\%) were milled by 2 hours to obtain the AlGr-1\% composites.

Next, the powder composites were sintered by the CM and HFIS methods. CM samples were cold compacted under $900 \mathrm{MPa}$ of pressure and subsequently sintered in a furnace at $550^{\circ} \mathrm{C}$ with a heating rate of $10^{\circ} / \mathrm{min}$ for 3 hours. Meanwhile, HFIS samples were compacted (450 $\mathrm{MPa})$ and sintered $\left(450^{\circ} \mathrm{C}\right)$ simultaneously for only 3 minutes.

The Fig.1 shows some micrographs of cold compacted powders (A), sintered by HFIS (B) and $\mathrm{CM}(\mathrm{C})$. With the milling process, the reinforcement particles are introduced in the metal matrix and the aluminum microstructure is refined (A). Using HFIS this condition is retained and graphite particles are embedded in the composite microstructure (B). In contrast, by CM not only the refined microstructure is negatively modified due to high temperature and long processing time, but also the formation of tiny precipitates of $\mathrm{Al}_{4} \mathrm{C}_{3}$ (Fig.2) occurs during the sintering process. 
References

[1] S Sivasankaran, K Sivaprasad, R Narayanasamy, PV Satyanarayana. Materials Characterization 62 (2011), p. 661.

[2] L Gómez, D Busquets-Mataix, V Amigo, MD Salvador. Compos. Mater. 43 (2009), p 987.

[3] LA Yolshina, RV Muradymov, IV Korsun, GA Yakovlev, SV Smirnov. Journal of Alloys and Compounds 663 (2016), p. 449.

[4] SN Alam, L Kumar. Materials Science \& Engineering A 667 (2016), p. 16.

[5] T Etter, P Schulz, M Weber, J Metz, M Wimmler. Journal of Materials Science and Engineering A 448 (2007), p. 1.

[6] CF Deng, DZ Wang, XX Zhang, AB Li. Materials Science and Engineering A 444 (2007), p. 138.
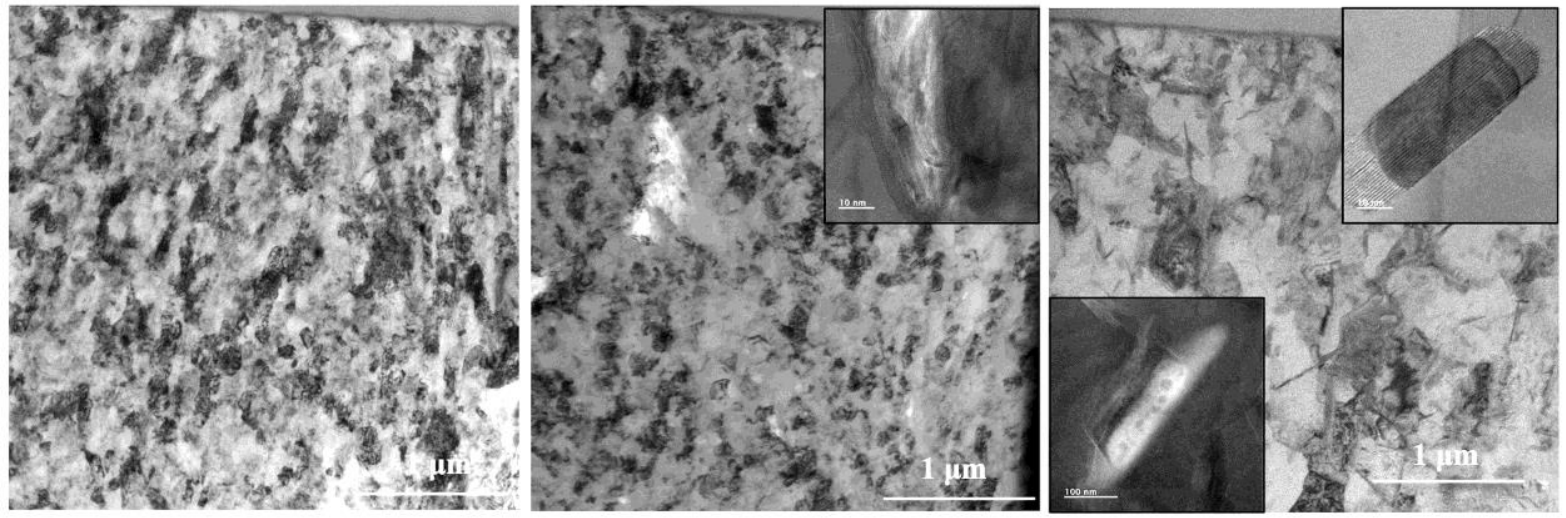

Figure 1. TEM-BF micrographs of AlGr-2h samples prepared by FIB: (A) cold compacted powder (without sintering process), (B) induction sintered and (C) conventional sintered. The magnified insets in sintered samples images correspond to the reinforcing particles.
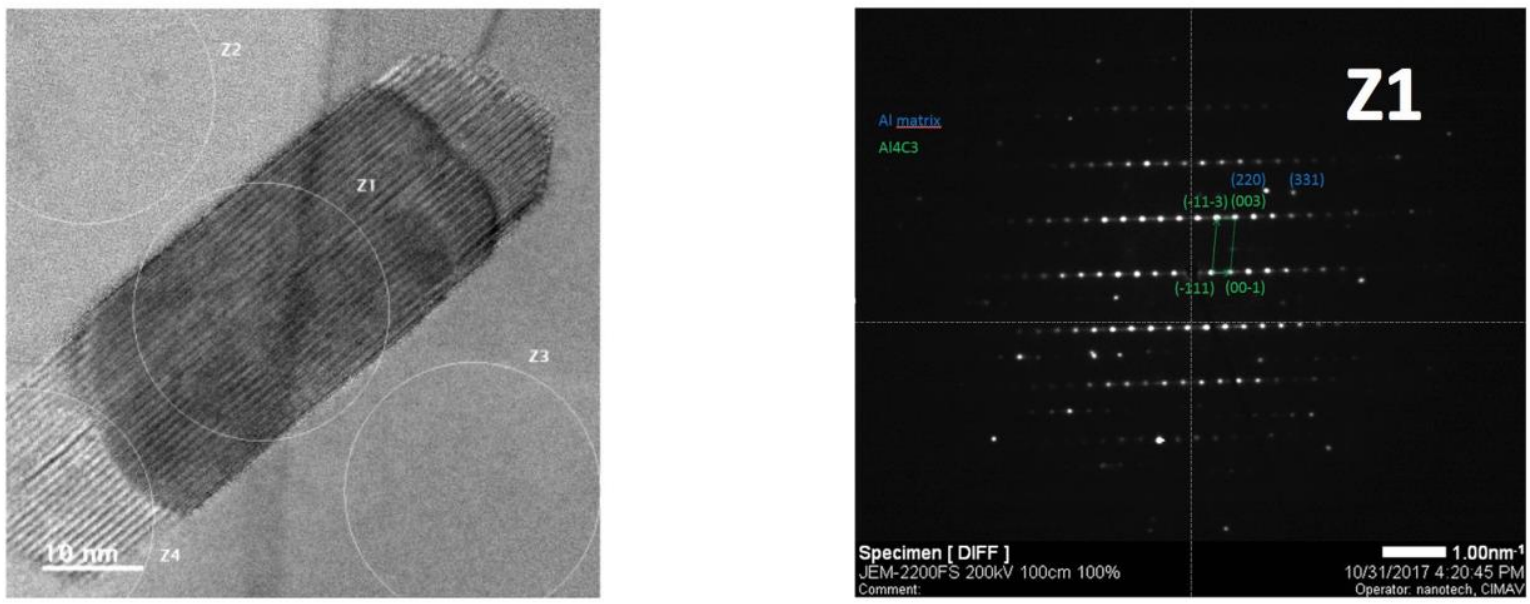

Figure 2. TEM-BF micrograph and $\mathrm{SAD}$ pattern of an $\mathrm{Al}_{4} \mathrm{C}_{3}$ submicron precipitate found in the AlGr-2h sample prepared by conventional sintering. This particle was clearly identified by the SAD pattern indexation. These structures are absent in the HFIS samples. 